\title{
In situ X-ray tomographic microscopy observations of vesiculation of bubble-free and bubble-bearing magmas
}

\author{
Mattia Pistone ${ }^{1,2,3} \cdot$ Luca Caricchi $^{4} \cdot$ Julie L. Fife $^{5} \cdot$ Kevin Mader $^{5,6} \cdot$ Peter Ulmer $^{1}$
}

Received: 26 July 2015 / Accepted: 21 November 2015 / Published online: 4 December 2015

(C) Springer-Verlag Berlin Heidelberg 2015

\begin{abstract}
Magma degassing is thought to play a major role in magma fractionation, transport, storage, and volcanic eruption dynamics. However, the conditions that determine when and how magma degassing operates prior to and during an eruption remain poorly constrained. We performed experiments to explore if the initial presence of gas bubbles in magma influences the capability of gas to escape from the magma. Vesiculation of natural $\mathrm{H}_{2} \mathrm{O}$-poor $(<<1 \mathrm{wt} . \%)$ silicic obsidian glasses was investigated by in situ, high-temperature (above the glass transition) experiments using synchrotron-based Xray tomographic microscopy with high spatial $(3 \mu \mathrm{m} /$ pixel $)$ and temporal resolution (1 second per 3D dataset). As a validation, a second set of experiments was performed on identical starting materials using a Karl-Fisher titration setup to
\end{abstract}

Editorial responsibility: J. Taddeucci

Electronic supplementary material The online version of this article (doi:10.1007/s00445-015-0992-1) contains supplementary material, which is available to authorized users.

Mattia Pistone

PistoneM@si.edu

1 Department of Earth Sciences, ETH - Zurich, Clausiusstrasse 25, CH-8092 Zurich, Switzerland

2 School of Earth Sciences, University of Bristol, Queen's Road BS8 1RJ, Bristol, UK

3 Department of Mineral Sciences, National Museum of Natural History, Smithsonian Institution, MRC-119, NHB, 10th Street \& Constitution Avenue NW, Washington, DC 20560, USA

4 Section of Earth and Environmental Sciences, University of Geneva, Rue des Maraîchers 13, CH-1205 Geneva, Switzerland

5 Swiss Light Source, Paul Scherrer Institute, Villigen, Switzerland

6 Institute for Biomedical Engineering, ETH - Zurich and University of Zurich, Zurich, Switzerland quantify the amount of extracted gas that escapes via volatile diffusion and/or bubble coalescence during vesiculation. In both sets of experiments, vesiculation was triggered by heating the samples at room pressure. Our results suggest that the presence of pre-existing gas bubbles during a nucleation event significantly decreases the tendency of bubbles to coalesce and inhibits magma outgassing. In contrast, in initially bubble-free samples, the nucleation and growth of bubbles is accompanied by significant coalescence and outgassing. We infer that volatile-undersaturated (i.e. bubble-free) magmas in the reservoirs are more likely to erupt effusively, while the presence of excess gas already at depth (i.e. bubble-bearing systems) increases the likelihood of explosive eruptions.

Keywords Magmas $\cdot$ Vesiculation $\cdot$ Bubbles $\cdot$ Degassing . Outgassing $\cdot$ Synchrotron $\cdot$ X-ray $\cdot$ Experiments $\cdot$ Volcanic eruption style

\section{Introduction}

The style and intensity of a volcanic eruption can be strongly affected by the efficiency of gas removal during the ascent of magma to the surface (Sparks 2003, and references therein). Gas exsolution in combination with increasing magma viscosity tends to generate overpressure in the gas bubbles, and if the excess gas is not readily removed from magma in this runaway process, an explosive eruption may occur (e.g. Melnik et al. 2005). The release of excess volatiles is fundamentally controlled by the coalescence of gas bubbles, the development of gas permeability, and magma brittle fracturing in the periods immediately preceding and/or occurring during an eruption. However, determining the numerous details and factors interacting and regulating the ability of magmas to degas is inherently complex because such processes occur at depth and 
in timescales that are not accessible with conventional experimental techniques, where the analysis of bubble textures is performed post-mortem, i.e. after gas escape and melt quenching, and, thus, after original gas bubbles become vesicles. Further, one of the fundamental questions of volcanology is whether or not it is possible to predict the likelihood of effusive versus explosive eruptions on the basis of the physical properties of magmas, such as rheology, volatile content, and rate of volatile exsolution (Fisher and Schmincke 1984).

Several experimental studies have been conducted to explore the mechanisms of gas exsolution and permeability (e.g. Larsen et al. 2004; Burgisser and Gardner 2005; Takeuchi et al. 2005) and to determine the conditions required for magma fragmentation (e.g. Mangan and Sisson 2000; Namiki and Manga 2005). Yet, in these studies only the final run products, representing the last "frame" of a dynamic process (e.g. Pistone et al. 2012, 2013). were analysed. Pioneering experiments, combining high-temperature devices and X-ray tomographic microscopy, have significantly contributed to understanding bubble formation and growth in basaltic (Bai et al. 2008; Baker et al. 2012) and felsic (Gondé et al. 2011; Okumura et al. 2013) systems, but have thus far not focused on the effect of pre-existing gas bubbles on the development of permeability.

In this study, we performed experiments at magmatic temperatures observing the vesiculation of bubbles and the development of gas permeability in three spatial dimensions and time (i.e. 4D), using a novel technique developed at the TOMCAT beamline of the Swiss Light Source at the Paul Scherrer Institut (Villigen, Switzerland; Stampanoni et al. 2006; Mokso et al. 2010; Fife et al. 2012; Pistone et al. 2015). In these experiments, we stimulate gas exsolution by increasing temperature for samples of different chemistries. In general, decompression is the principal cause of magma vesiculation during volcanic eruptions. Although our experiments do not simulate magma decompression, they nevertheless offer important insights into the dynamics of magma vesiculation in $\mathrm{SiO}_{2}$-rich systems and constrain how the initial volatile saturation conditions of magmas (i.e. the presence or absence of gas bubbles) can potentially affect the style of degassing and, thus, the style of a volcanic eruption.

\section{Experimental and analytical techniques}

\section{Starting materials and Karl-Fischer titration}

Five natural samples of obsidian were selected as starting materials:

- Two samples from Lipari Island (Acqua Calda, LIP, and Rocche Rosse, LIP2, Aeolian Islands, Italy; Gottsmann and Dingwell 2001)

- A sample from Little Glass Mountain (Medicine Lake Highland, California, USA; LGM; Fink 1983)
- A sample from Mayor Island (New Zealand; MI; Stevenson et al. 1993)

- A sample from Las Cañadas Caldera (Tenerife, Canary Islands, Spain; CAN; Fife et al. 2012; Madonna et al. 2013).

LIP, LIP2 and LGM are bubble-free, whereas MI and CAN are bubble-bearing (bubble fraction, $\beta=0.02$ in MI, and $\beta=$ 0.04 in CAN; bubble fraction estimated by three-dimensional analysis; see below). LIP, LIP2, LGM, and MI are metaluminous rhyolites in the TAS diagram (Le Maitre et al. 2002; Fig. 1) whereas the CAN sample is a peralkaline phonolite (see also Table 1A in Appendix).

The initial $\mathrm{H}_{2} \mathrm{O}$ contents of the samples ( $\mathrm{LIP}=0.54$ wt.\%; LIP2 $=0.25$ wt. $\%$; LGM=0.10 wt. $\%$; MI=0.24 wt. \%; CAN= 0.23 wt.\%) and the amounts of $\mathrm{H}_{2} \mathrm{O}$ extracted at different temperatures were determined by Karl-Fischer titration (KFT; Fischer 1935; Behrens et al. 1996) using a CA 100 Moisture Meter (COSA Instruments, Mitsubishi Chemical Corporation), which uses high purity argon stream as carrier transporting $\mathrm{H}_{2} \mathrm{O}$ from the heated sample to the titration cell. Samples were heated up from 573 to $1523 \mathrm{~K}$ at constant heating rate of $2 \mathrm{~K} / \mathrm{s}$ (for fine-grained powders) to $10 \mathrm{~K} / \mathrm{s}$ (for glasses) using a Linn High Therm HTG-REG controller, and a total titration time of minutes was applied during KFT analysis. Precision and accuracy of the equipment were tested by calibration measurements, with an individual measurement error of $\pm 0.003-0.005$ wt.\%, and a precision of replicate analysis of \pm 0.05 wt. $\% \mathrm{H}_{2} \mathrm{O}$ (Pistone et al. 2012, 2015). Since the melt viscosity $\left(\eta_{\text {melt }}\right)$ of the samples was rather high $\left(\eta_{\text {melt }}>10^{5} \mathrm{~Pa} \cdot \mathrm{s}\right.$ at $\left.<1523 \mathrm{~K}\right)$, to determine the total initial $\mathrm{H}_{2} \mathrm{O}$ content of the samples, finegrained powders of the samples were mixed with $\mathrm{Li}_{2} \mathrm{~B}_{4} \mathrm{O}_{7}$ powder (Merck Chemicals, Switzerland), with a ratio of 1:5. During analysis this procedure lowers the liquidus temperatures of the glasses, their viscosities and enables complete $\mathrm{H}_{2} \mathrm{O}$ extraction from the melt even at low water contents, which promote slow diffusion (Zhang et al. 1991; Behrens et al. 1996). Since $\mathrm{Li}_{2} \mathrm{~B}_{4} \mathrm{O}_{7}$ is extremely hygroscopic, KFT analyses began at $573 \mathrm{~K}$ to avoid contamination by adsorbed $\mathrm{H}_{2} \mathrm{O}$ from external moisture. The residual $\mathrm{H}_{2} \mathrm{O}$ in $\mathrm{Li}_{2} \mathrm{~B}_{4} \mathrm{O}_{7}$ was separately determined at various temperatures and used to correct the $\mathrm{H}_{2} \mathrm{O}$ content of the single sample in the same temperature range. KFT measurements were additionally performed on glass cylinders with dimensions similar to those used for the X-ray tomographic microscopy experiments (see next paragraph) to quantify the amount of $\mathrm{H}_{2} \mathrm{O}$ released from the samples during bubble nucleation and growth.

The main samples of this study are LIP and MI, which were chosen as proxies for volatile-undersaturated (bubble-free LIP) and volatile-saturated magmas (bubble-bearing MI, $\beta=$ 0.02 ). Differently from the microstructural analyses reported in the work of Rust et al. (2003). the MI sample displays an initial average bubble size of 10-20 $\mu \mathrm{m}$ and bubbles having 


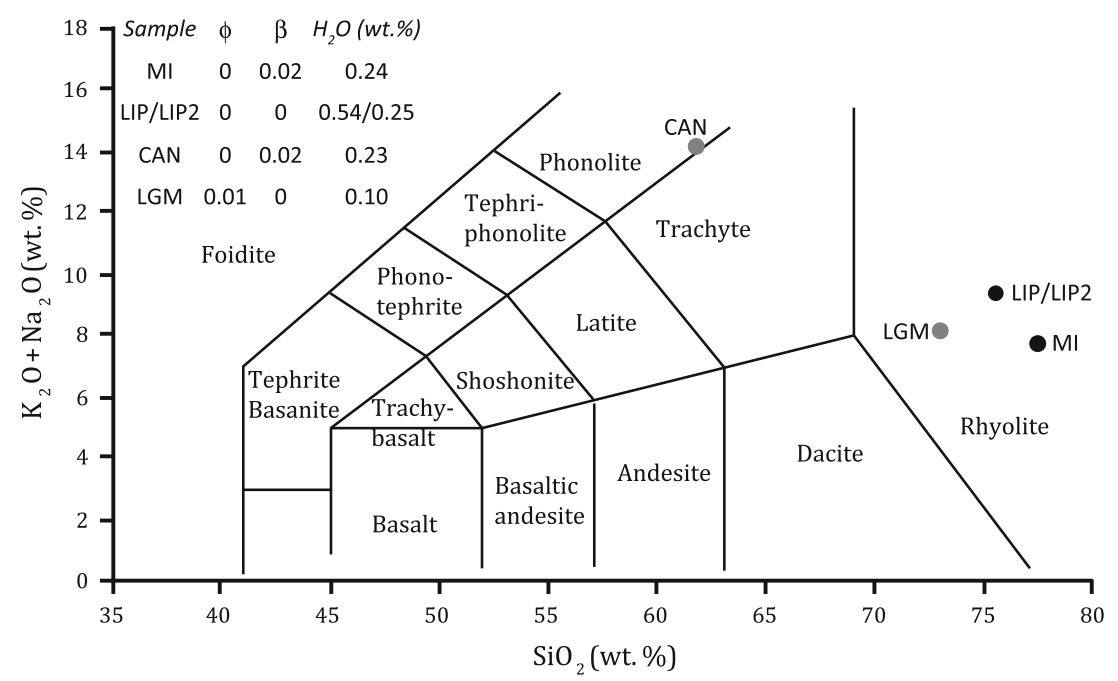

Fig. 1 TAS diagram (Le Maitre et al. 2002, modified) displaying the natural obsidian samples investigated in this contribution. Black dots indicate the primary samples simulating volatile-undersaturated (LIP) and volatile-saturated (MI) systems, respectively. Grey dots indicate the samples testing the effect of composition (CAN), the initial $\mathrm{H}_{2} \mathrm{O}$ content (LIP2) and the presence of chemical heterogeneities (i.e. Fe-Ti oxides; LGM) on gas exsolution. Specifically, the CAN and LGM samples are used for comparison with the MI and LIP samples, respectively. Abbreviations: $\phi=$ solid crystal volume fraction; $\beta=$ gas bubble volume fraction; $\boldsymbol{H}_{2} \boldsymbol{O}=$ initial $\mathrm{H}_{2} \mathrm{O}$ content dissolved in the glass phase, expressed in wt.\%. Reported data are volatile-free basis. The different samples display the following agpaitic indices (i.e. molar ratio $\mathrm{Al}_{2} \mathrm{O}_{3} /\left[\mathrm{Na}_{2} \mathrm{O}+\right.$ $\left.\mathrm{K}_{2} \mathrm{O}\right]$ ): LIP and LIP2=1.03; $\mathrm{MI}=1.16 ; \mathrm{LGM}=1.27 ; \mathrm{CAN}=0.96$

and $2 \mathrm{~mm}$ length) in portions of the natural obsidian glasses displaying homogeneous aspect (e.g. bands of larger size than the sample core). Minor differences in the chemical properties between the samples (e.g. alkalis content, initial $\mathrm{H}_{2} \mathrm{O}$ content) could also contribute to differences in the behaviour of bubble nucleation and growth (i.e. local heterogeneous bubble nucleation) observed during experiments.

Because viscosity differences, along with volatile diffusivity (Sparks et al. 1994). tend to affect the bubble nucleation rate (Murase and McBirney 1973). care was taken that the samples employed in this study have similar melt viscosities (i.e. less than $2 \log$ units in $\eta$ melt difference in the range $10^{5}$ $10^{13} \mathrm{~Pa} \cdot \mathrm{s}$; see next section) in the temperature window investigated. Utilising relatively high viscosity $\left(\eta_{\mathrm{melt}}>10^{5} \mathrm{~Pa} \cdot \mathrm{s}\right)$ materials has several advantages, most importantly their difficulty to crystallise at super solidus temperatures and their relatively sluggish bubble nucleation and growth kinetics that allowed for capturing 4D image sequences with minimal movement artefacts during X-ray tomographic microscopy upon continuously-increasing temperature (see next section). Finally, the low $\mathrm{H}_{2} \mathrm{O}$ content of our samples permitted us to focus on melts with initial super solidus viscosities $\left(\eta_{\text {melt }}>\right.$ $\left.10^{5} \mathrm{~Pa} \cdot \mathrm{s}\right)$ that are characteristic for the pre-fragmentation stage in volcanic eruptions of $\mathrm{SiO}_{2}$-rich systems.

\section{Experimental setup and synchrotron-based X-ray tomographic microscopy}

Samples for the 4D X-ray tomographic microscopy experiments were obtained by drilling cylindrical cores of $2 \mathrm{~mm}$ 
Fig. 2 Back scattered electron (BSE) and characteristic EDSbased X-ray distribution maps of the LIP sample obtained by SEM at $25 \mathrm{kV}$ acceleration voltage and $10 \mathrm{nA}$ beam current. Colour scales of the X-ray distribution maps are expressed in wt.\%. Maps reveal minor chemical variability $(\mathrm{Ca}, \mathrm{K}, \mathrm{Na})$ that are not found in the other natural obsidian glasses used in this study
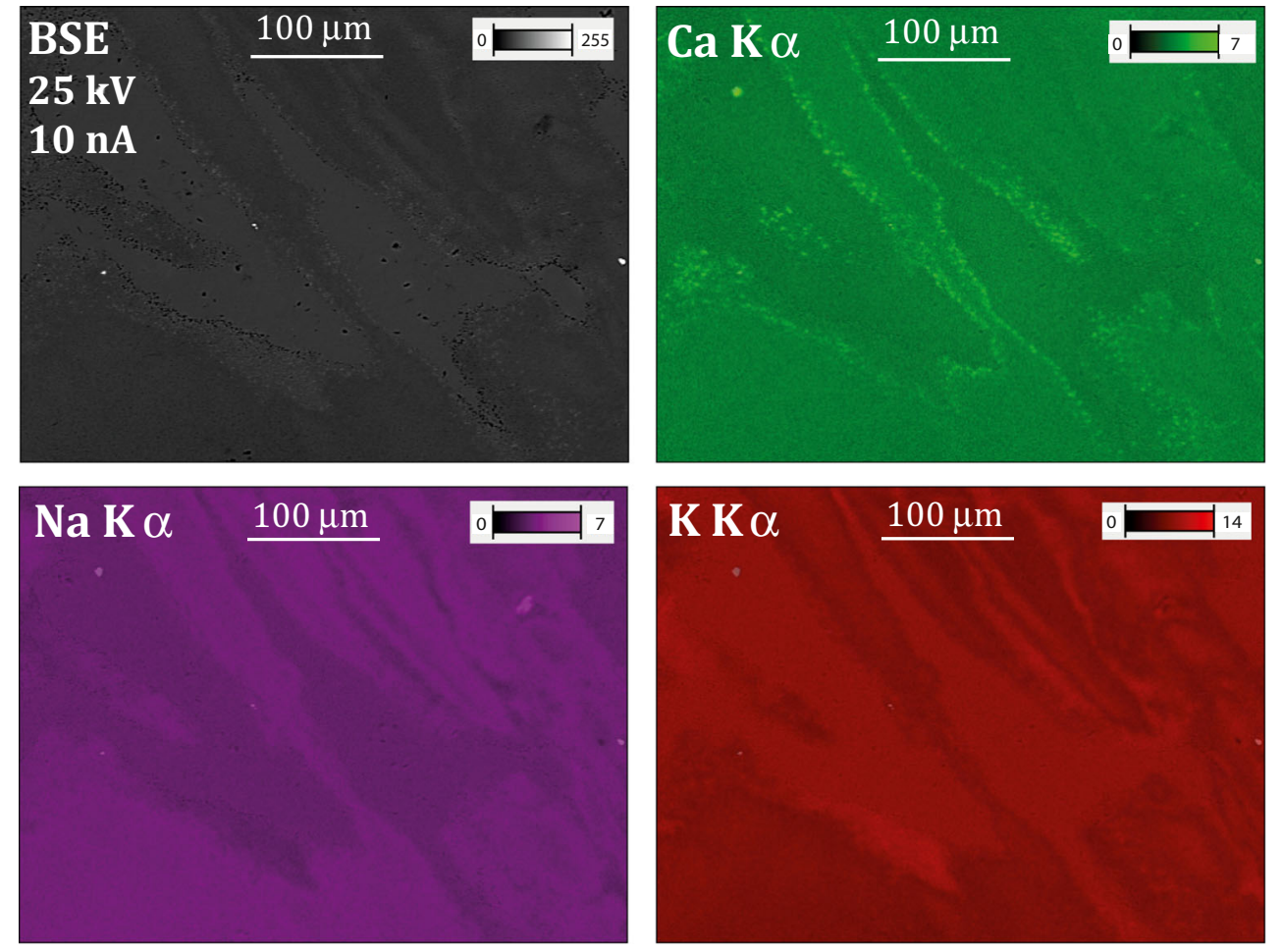

outer diameter and $2 \mathrm{~mm}$ length from the natural obsidians. The sample was then inserted into a hot-pressed boron nitride (BN) holder (4 $\mathrm{mm}$ outer diameter, $2.2 \mathrm{~mm}$ inner diameter; Fig. 3), which was attached to a zirconia rod on the rotation stage at the TOMCAT beamline of the Swiss Light Source. $\mathrm{BN}$ is used as the sample holder because it is largely X-ray transparent and features excellent thermal and chemical stability (up to $1273 \mathrm{~K}$ in air) and relatively high thermal conductivity (20-60 $\mathrm{Wm}^{-1} \mathrm{~K}^{-1}$; Wiley-VCH 1999; Mortazavi et al. 2015). The sample is predominantly homogeneous, with no major variations in the bubble volume fraction or size distribution along the length of the specimen; thus, heat transfer to the sample through the BN wall (0.9 mm thickness) appeared to be rapid and efficient. Using Fourier's law of heat conduction, a minimal temperature differential $(<10 \mathrm{~K})$ was calculated along the height of sample as long as the sample remained within the $\mathrm{BN}$ holder ( $5 \mathrm{~mm}$ height). Radial thermal gradients are considered even lower due to continuous rotation during $\mathrm{X}$-ray tomographic microscopy acquisition and the sample located at the centre of the X-shaped laser setup (Fife et al. 2012). In cases where the sample expanded outside the $\mathrm{BN}$ holder (such as 'mi2 ' in Table 1B in the Appendix), the protruding portion was almost certainly at a lower temperature than the rest of the sample and therefore excluded from subsequent analyses.

Data were acquired using the ultra-fast endstation at the TOMCAT beamline (Stampanoni et al. 2006; Mokso et al. 2010) coupled with the laser-based heating system available at TOMCAT (Fife et al. 2012). This setup utilises a high-flux source of polychromatic X-rays or "white beam" radiation filtered to $5 \%$ power and the high speed pco.DIMAX camera with a tunable microscope adjusted to approximately four times magnification. As such, a 3D dataset consisting of 1000 projections were captured over $180^{\circ}$ of rotation in $1 \mathrm{~s}$ with an isotropic pixel size of $2.96 \mu \mathrm{m}$. Two different acquisition modes were employed to ultimately capture the dynamics of bubble evolution: (1) a single scan of the sample acquired at a single temperature; and (2) continuous scans of the sample during heating at a specified rate. All experiments were conducted above the glass transition temperature of the respective samples $(\mathrm{LIP}=885 \mathrm{~K} ; \mathrm{MI}=865 \mathrm{~K} ; \mathrm{CAN}=849 \mathrm{~K}$; $\mathrm{LGM}=975 \mathrm{~K}$; as estimated using the model of Giordano et al. 2008). sample LIP2 was not investigated in the X-ray tomographic microscopy experiments.

\section{Laser-based heating system}

The laser-based heating system, developed by Fife et al. (2012). is composed of two near-infrared (IR) diode lasers, operating at a wavelength of $980 \mathrm{~nm}$ and a maximum power output of $150 \mathrm{~W}$ each (Apollo Instruments, Irvine, CA, USA). Each laser illuminates a rectangular spot of $0.2 \mathrm{~mm}$ high $\times 1$ $\mathrm{mm}$ wide at the proper working distance of the optics, which can spread to larger spot sizes depending on the size of the specimen placed in the laser paths. We utilised a sample holder made of BN, which essentially worked as high-temperature furnace during the experiments (Fig. 3). Two visible laser spots are used to determine the location of the laser heating 


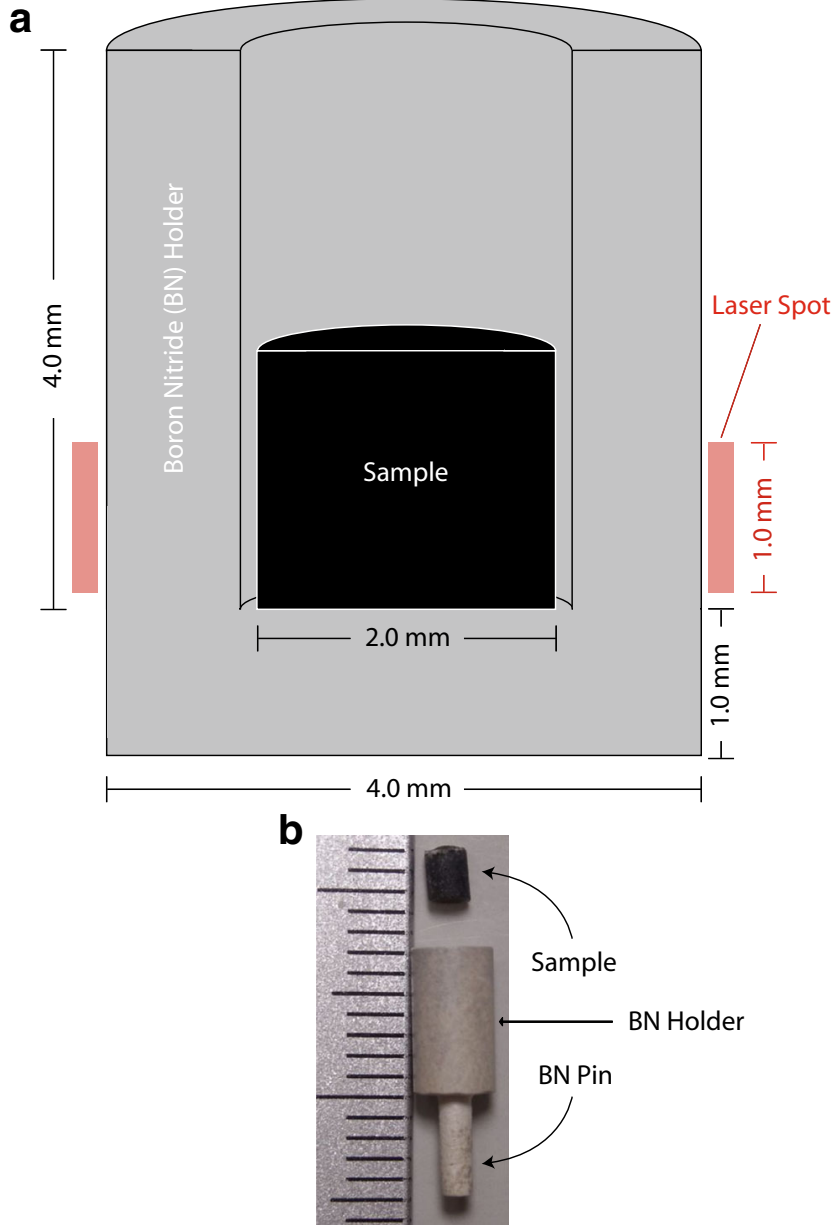

Fig. 3 (a) Schematic and (b) actual images of the experimental setup used in combination with the ultra-fast data acquisition endstation (Mokso et al. 2010) and the laser-based heating system (Fife et al. 2012) at the TOMCAT beamline (Stampanoni et al. 2006)

on the sample. The temperature is recorded by a non-contact pyrometer (Optris; Berlin, Germany). The pyrometer is a class 2 IR laser that filters out IR and near-IR wavelengths such that the diode lasers are invisible to the temperature reading. The pyrometer records the temperature of the sample within its line-of-sight based on thermal changes in its spot, within $0.1 \mathrm{~K}$ in the range of 623-1973 K (Fife et al. 2012).

\section{Three-dimensional microstructural analysis}

The 4D $(3 \mathrm{D}+$ time $)$ tomographic datasets were processed using a collection of different tools for quantitative analysis and visualisation. To convert the original tomographic projections into binary images, a simple grey levels threshold was combined with morphological operations as described in Mader et al. (2012). For surface-based analyses, customised codes in Interactive Data Language (IDL) were used. The 3D renderings were made with both IDL and Avizo ${ }^{\circledR}$ software (Visualization Sciences Group). For the quantitative analysis of volumetric shapes and features, a custom set of algorithms that labelled individual regions of the cellular material (i.e. gas bubbles) were used (Mader et al. 2012). To calculate these metrics, a shape tensor was computed for each bubble. The shape tensors were calculated using covariance of the voxel positions belonging to each bubble (Mader et al. 2012, and references therein). The tensor was visualised as an ellipsoid with 3 principal axes (eigenvectors) and 3 lengths for each axis (eigenvalues). The degree of anisotropy was calculated as the ratio of the difference between the longest and shortest axes and the longest axis of the bubble, with the latter resulting in a number between 0 (spherical) and 1 (infinite). From these metrics, specific values for bubble dimensions, radii, bubble connectivities, and anisotropies were quantified and compared. When applied to a time series of dynamic data, the movements, volumes, and anisotropies of individual gas bubbles could be tracked with increasing time and temperature. The resulting 4D microstructure evolutions of samples LIP and MI can be seen in Movies 1 and 2, respectively (see Appendix). The volume fraction of bubbles $(\beta)$ in the sample is determined as the ratio between the volume of bubbles and the total sample volume (volume of bubbles + volume of melt; Gardner et al. 1999).

\section{Results}

\section{KFT experiments}

The results obtained for the extraction of $\mathrm{H}_{2} \mathrm{O}$ from glass cylinders reveal many similarities but also some striking differences between samples (Fig. 4). Heating glass cylinders of the Lipari obsidians (LIP and LIP2) resulted in the progressive loss of about $0.14 \mathrm{wt} . \% \mathrm{H}_{2} \mathrm{O}$ corresponding to $26 \%$ extraction of the total initially dissolved $\mathrm{H}_{2} \mathrm{O}$ (LIP, Fig. 4a). Conversely, no detectible amount of $\mathrm{H}_{2} \mathrm{O}$ is extracted from the glass cylinder of sample LGM (Fig. 4a). Measurements performed on glass cylinders of samples $\mathrm{MI}$ and $\mathrm{CAN}$ under identical conditions, also did not record any $\mathrm{H}_{2} \mathrm{O}$ extraction from the samples during heating (Fig. 4b). Interestingly, the samples with the lower calculated $\eta_{\text {melt }}$ are the samples where no $\mathrm{H}_{2} \mathrm{O}$ was extracted during heating, except LGM sample (Fig. 4c). For all powdered samples, the total amount of $\mathrm{H}_{2} \mathrm{O}$ extracted is significantly larger than the amount extracted from glass cylinders, and we consider the final value of $\mathrm{H}_{2} \mathrm{O}$ released at the highest temperature $(1523 \mathrm{~K})$ as the total $\mathrm{H}_{2} \mathrm{O}$ content of the specimens. Based on the melt chemistry and KFT-measured $\mathrm{H}_{2} \mathrm{O}$ content, $\eta_{\text {melt }}$ for each sample was calculated using the model of Giordano et al. (2008). $\eta_{\text {melt }}$ of each sample decreases with temperature by 5 orders of magnitude within the temperature window of the tomography experiments (grey area in Fig. 4c). The range of isothermal $\eta_{\text {melt }}$ of all samples does not exceed more than $2 \log$ units (Fig. 4c) at all temperatures considered. 

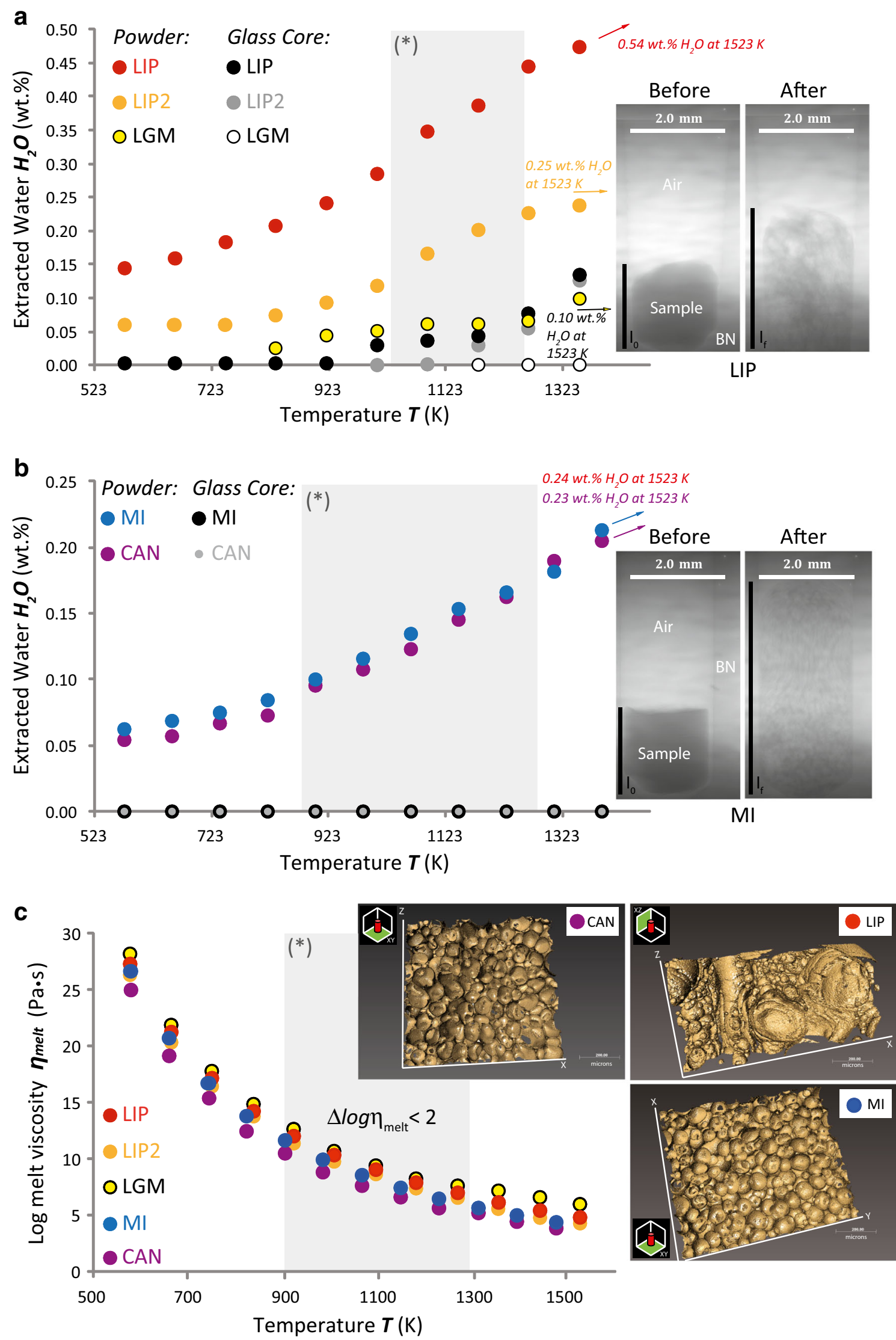

$(*)=$ Conditions of the in situ $4 D$ high-temperature synchrotron-based $X$-ray tomographic microscopy experiments at the TOMCAT beamline of SLS 
4 Fig. 4 Amounts of extracted $\mathrm{H}_{2} \mathrm{O}$ as measured by Karl-Fisher titration (KFT) at different temperatures $(\boldsymbol{T})$ in a fine-powdered sample and in solid glass cylinders of the: (a) LIP, LIP2 and LGM; and (b) MI and CAN samples. The image insets in $\mathbf{a}$ and $\mathbf{b}$ are $2 \mathrm{D}$ X-ray projection images of the LIP and MI samples before and after heating. (c) The evolution of melt viscosity $\left(\boldsymbol{\eta}_{\boldsymbol{m} \text { elt }}\right)$ as a function of $\boldsymbol{T}$ for the CAN, LIP and MI specimens, with $\boldsymbol{\eta}_{\text {melt }}$ estimated using the model of Giordano et al. (2008). and considering the $\mathrm{H}_{2} \mathrm{O}$ content in the residual melt for a specified $\boldsymbol{T}$, taken from the amounts of extracted $\mathrm{H}_{2} \mathrm{O}$ in $\mathbf{a}$ and $\mathbf{b}$. The inset images in $\mathbf{c}$ show $3 \mathrm{D}$ renderings of post-mortem microstructures of the LIP, MI and CAN samples. $\boldsymbol{l}_{\boldsymbol{\theta}}$ and $\boldsymbol{l}_{\boldsymbol{f}}$ reported in the inset images in $\mathbf{a}$ and $\mathbf{b}$ indicate initial and final lengths of the LIP and MI samples before and after heating, respectively. The grey-coloured areas in $\mathbf{a}, \mathbf{b}$, and $\mathbf{c}$ represent the temperature range of the dynamic X-ray tomographic microscopy experiments

\section{X-ray tomographic microscopy experiments}

The 3D tomographic renderings illustrate the profound change of bubble texture during heating (Fig. 5) recorded by continuous image acquisition (Movies 1-2). No crystallisation occurred during vesiculation in any sample. It should be noted that Fig. $5 \mathrm{~d}$ is a rendering of the bubbles present in the MI sample prior to heating, whereas all other renderings in Fig. 5 are those of the melt phase.

The final microstructure of the LIP sample after heating (Fig. 5c) reveals a distribution of gas bubbles including large unconnected sub-spherical bubbles and relicts of gas channels composed of vertically elongated small bubbles. The generation of gas channels by bubble coalescence is confirmed by the increase of bubble anisotropy in the LIP sample at the initial stage of heating (Fig. 6a). The peak anisotropy at $1088 \mathrm{~K}$ is associated with an increase of $\beta$ up to almost 0.4 (Fig. 6a). Most bubble nucleation and growth occurred between $1073 \mathrm{~K}$ (starting temperature) and $1088 \mathrm{~K}$, which generated a dramatic increase in vesicularity from bubble-free to $\beta=0.35$ (Fig. 6a). The dynamics of this initial burst of vesiculation was too rapid to be captured on the timescale of the data acquisition; this, together with the simultaneous dominant bubble coalescence process, which could have "overwritten" the signature of the initial bubble nucleation and growth, does not allow us to confirm if incipient heterogeneous bubble nucleation operated at the initial stage of vesiculation in the LIP sample. As the temperature increases to $1103 \mathrm{~K}$, the anisotropy significantly decreases; meanwhile, $\beta$ increases slowly to 0.47 (Fig. 6a). With further heating to $1268 \mathrm{~K}$, the slow and modest increase of $\beta$ is explained by a further increase in the volume of gas being largely accommodated by permeable flow out of the sample. The $\beta$ and number of bubbles continuously evolve but these changes were minor compared to the initial microstructure changes up to $1088 \mathrm{~K}$ despite the substantial loss of $\mathrm{H}_{2} \mathrm{O}$ over the duration of vesiculation as recorded by the KFT experiments (Fig. 4a).

In the LIP sample, diffuse bubble coalescence occurs predominantly through melt film thinning by stretching between expanding gas bubbles (Castro et al. 2012; Fig. 5a-c; Movie 1 ). In addition, bubble coalescence is the controlling process generating gas channels (see image insets in Figs. $4 \mathrm{c}$ and 6a) that serve as permeable pathways for gas escape. Further expansion of the remaining unconnected bubbles, bubble-poor sample portions, and loci of previous degassing pathways suffer local deformation (see the yellow-boxed portion of the LIP sample in Fig. 5a-c and Movie 1, representing a shear band composed of stretched $100 \mu \mathrm{m}$ long bubbles), generating fabrics similar to those observed in natural pumices (Klug et al. 2002; Wright and Weinberg 2009). Overall, bubble connectivity induced by bubble coalescence in the LIP sample introduces anisotropy (Fig. 6a), which masks the simultaneous isotropic expansion of gas bubbles. Bubble coalescence and outgassing can further be detected by analysing the bubble number density $(\mathrm{BND}=$ number of bubbles per melt volume; Gaonac'h et al. 2005) as a function of temperature (Fig. 7a). BND in the LIP sample stays nearly constant for the experimental duration starting from $1188 \mathrm{~K}$ (Fig. 6a) due to the competition between bubble coalescence and gas removal (that should decrease BND) and nucleation and growth of novel gas bubbles (that should increase BND). The extent of bubble coalescence and gas loss in the LIP sample are consistent with the trend of cumulative 3D BND (Fig. 7b).

The evolution of bubble textures observed in the MI sample during heating is very different from the observations of the LIP sample and can be attributed to two principal processes: (i) change of shape of pre-existing prolate bubbles towards spherical bubbles (up to $967 \mathrm{~K}$ ) and (ii) nucleation and growth of new gas bubbles (Fig. 6b). Gas expansion promotes strong vertical inflation of the sample, which results in a foam structure that is at least twice the initial length and volume of the original sample (see the inset images in Fig. 4b). During heating, the central portion of the MI sample transforms into a mono-dispersed bubbly suspension, with gas bubbles having an average diameter of about 200-300 $\mu \mathrm{m}$ (Fig. 5d-f; Movie 2). Bubbles are not interconnected but instead impinge on each other along melt films and at the three neighbouring bubble edges or Plateau borders that separate the melt films (Bikerman 1973; Kraynik 1988). This generates a polygonal network (see image inset in Fig. 4c), which resembles the structures found in felsic frothy pumices. A thin melt film is assumed to separate the bubbles and prevent coalescence (Fig. 5d-f; Movie 2), although at the spatial resolution of the scans (approximately $9 \mu \mathrm{m}$, based on a minimum of three pixels $[2.96 \mu \mathrm{m} /$ pixel $]$ representing a feature in the microstructure), this may not be adequately resolved. The absence of significant outgassing is furthermore evidenced by the large increase of bubble fraction from 0.02 to 0.87 , accompanied by a change in bubble shape from prolate to sub-spherical at 1057 K (Fig. 6b, Movie 2). The slight increase of the bubbles anisotropy at the highest temperatures (1207-1297 K; Fig. 6b) is due to the vertical expansion of the sample (inset in Fig. 6b) 
Fig. 5 3D renderings of: (a-c) the LIP sample, showing the melt phase in green while the bubbles are transparent; and (d-f) the MI sample, showing the melt phase in gold while the bubbles are transparent (except in $\mathbf{d}$ where, because bubble volume fraction is low, the bubbles are shown in gold and the melt is transparent). The bottom right corner of each subfigure indicates the temperature $(\boldsymbol{T})$ and the bubble fraction $(\boldsymbol{\beta})$ for the image. The yellow-boxed portions in the LIP sample subfigures highlight bubble coalescence (a), outgassing (b), and shear banding of residual bubbles that were not outgassed (c). The $3 D$ renderings of the LIP and MI samples are based on the dynamic experiments carried out at the TOMCAT beamline. Specifically, heating rates were: $15 \mathrm{~K} / \mathrm{s}$ in the temperature range 1073-1268 K for the LIP sample and $28 \mathrm{~K} / \mathrm{s}$ in the temperature range 907$1303 \mathrm{~K}$ for the MI sample. 3D renderings of the CAN sample are reported in the studies of Fife et al. (2012) and Madonna et al. (2013). 3D renderings of the LGM sample are reported in Pistone (2012). The LIP2 sample was not investigated in the X-ray tomographic microscopy experiments
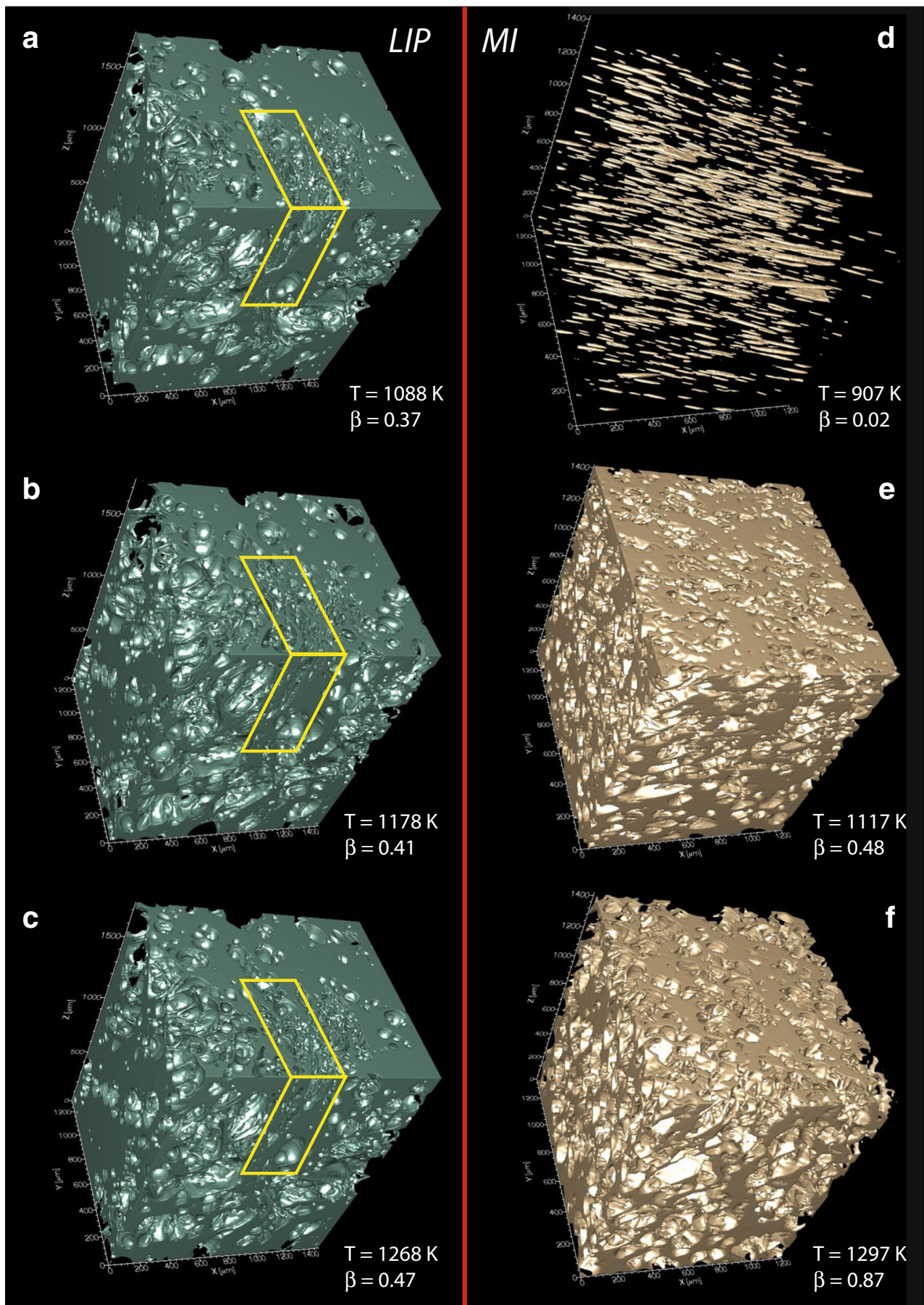

and bubble impingement at $\beta>0.74$. BND in the MI sample sharply increases from 967 to $1147 \mathrm{~K}$, followed by a slight decrease to $1237 \mathrm{~K}$, and stabilises until the end of the run (Fig. 7c). Between 1147 and $1237 \mathrm{~K}$, the decrease of BND can be associated with local bubble connectivity not accompanied by gas removal (Fig. 6b). The general trend of the cumulative $3 \mathrm{D}$ bubble size distribution suggests that nucleation and growth of bubbles via gas expansion dominate during heating (Fig. 7d). The volume concentration of larger bubbles increases (radius of 110-130 $\mu \mathrm{m}$ ), and a wide distribution of bubble sizes between 90 and $130 \mu \mathrm{m}$ (about 70 vol.\%) develops, which strongly differs from the initial bubble size distribution (Fig. 8a).

The LGM and CAN samples used in this study display different behaviour during gas exsolution compared to the LIP and MI samples. The LGM sample only exhibits very limited bubble nucleation and growth $(\beta<0.03)$ close to the sample periphery, with no observable bubble anisotropy (Fig. 6a). No microlites of 
Fig. 6 Absolute bubble anisotropy (red and orange lines) and bubble volume fraction (light and dark green dots) as a function of temperature for: (a) LIP and LGM; and (b) MI and CAN samples. Schematic drawings highlight the principal microstructural results during high temperature vesiculation.

The image inset in a provides a $3 \mathrm{D}$ rendering of the LIP sample containing a gas channel promoting outgassing (see red arrow). The image inset in $\mathbf{b}$ reveals the large expansion of the MI sample during vesiculation a
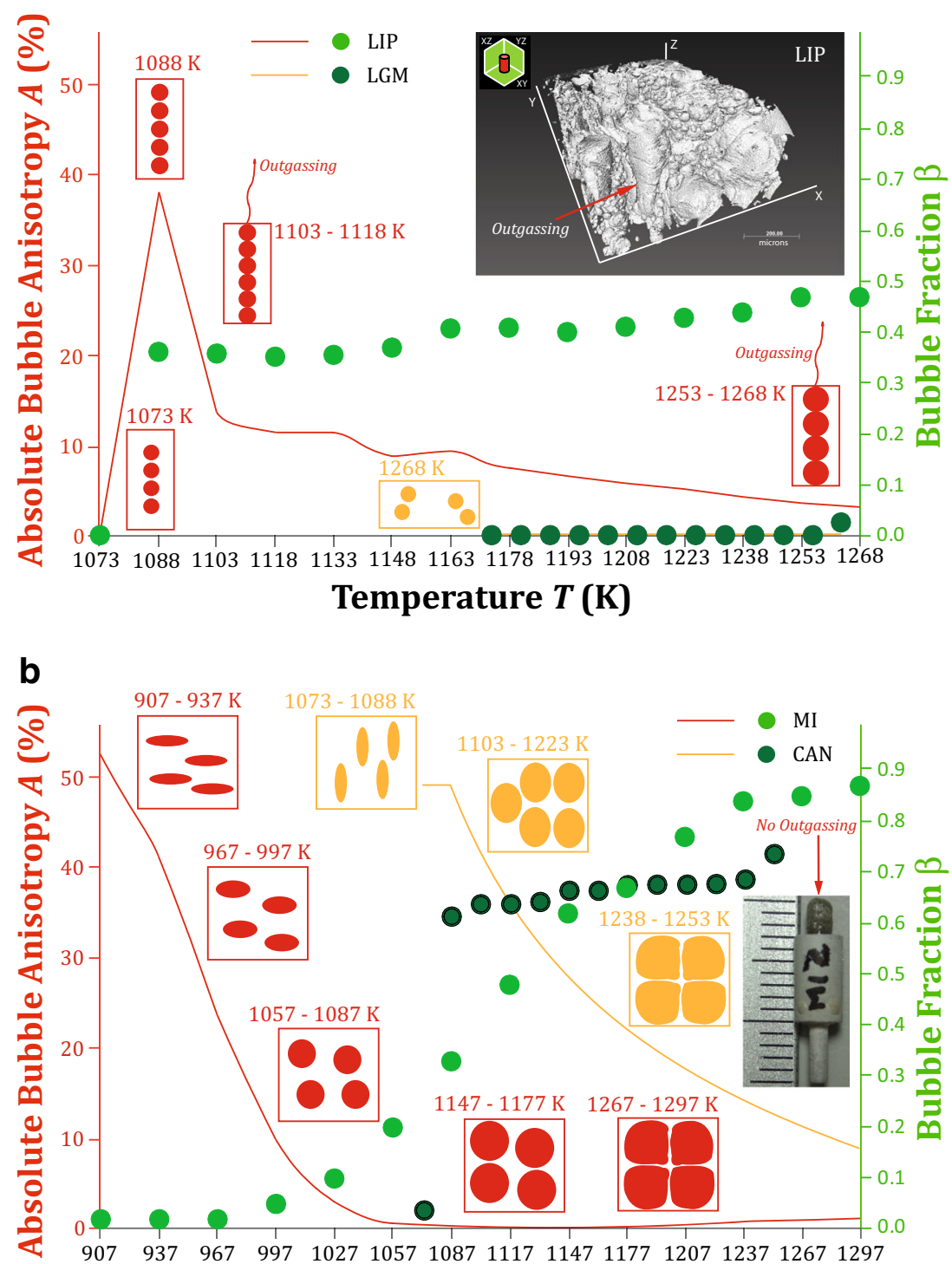

Temperature $T(\mathrm{~K})$
Fe-Ti oxide can be detected at the spatial resolution of the X-ray tomographic microscopy experiments $(2.96 \mu \mathrm{m} / \mathrm{pixel})$; thus, we are not able to quantify the dynamics of heterogeneous bubble nucleation and growth from preferential microlite sites, as it was observed in previous studies (e.g. Hurwitz and Navon 1994). The CAN sample displays a polygonal network of gas bubbles similar to that of the MI sample (see image inset in Fig. 4c; additional textural information can be found in the studies of Fife et al. 2012, and Madonna et al. 2013) when $\beta \sim 0.65$ (Fig. 6b). However, the CAN sample experiences a sharp increase of vesiculation similar to that of the LIP sample, with an initial gas burst followed by a smooth increase of $\beta$ up to 0.74 when gas bubbles start to impinge on each other (Fig. 6b). Residual bubble anisotropy is observed even at the highest temperature (Fig. 6b).

\section{Discussion}

\section{Bubble nucleation and growth in highly viscous, water-poor silicic magmas}

The rate of bubble growth is a function of the concentration of volatiles, rate of gas diffusion, viscosity of the surrounding melt, bubble surface tension, and gas overpressure (Gonnermann and Manga 2007, and references therein). At constant pressure and in stationary melt, two processes control bubble growth: (i) diffusion of $\mathrm{H}_{2} \mathrm{O}$ molecules from the bulk of the supersaturated melt towards the bubble-melt interface (diffusion-limited bubble growth); and (ii) expansion of the bubble by viscous deformation of the surrounding melt (viscosity-limited bubble growth; Navon et al. 1998). The 

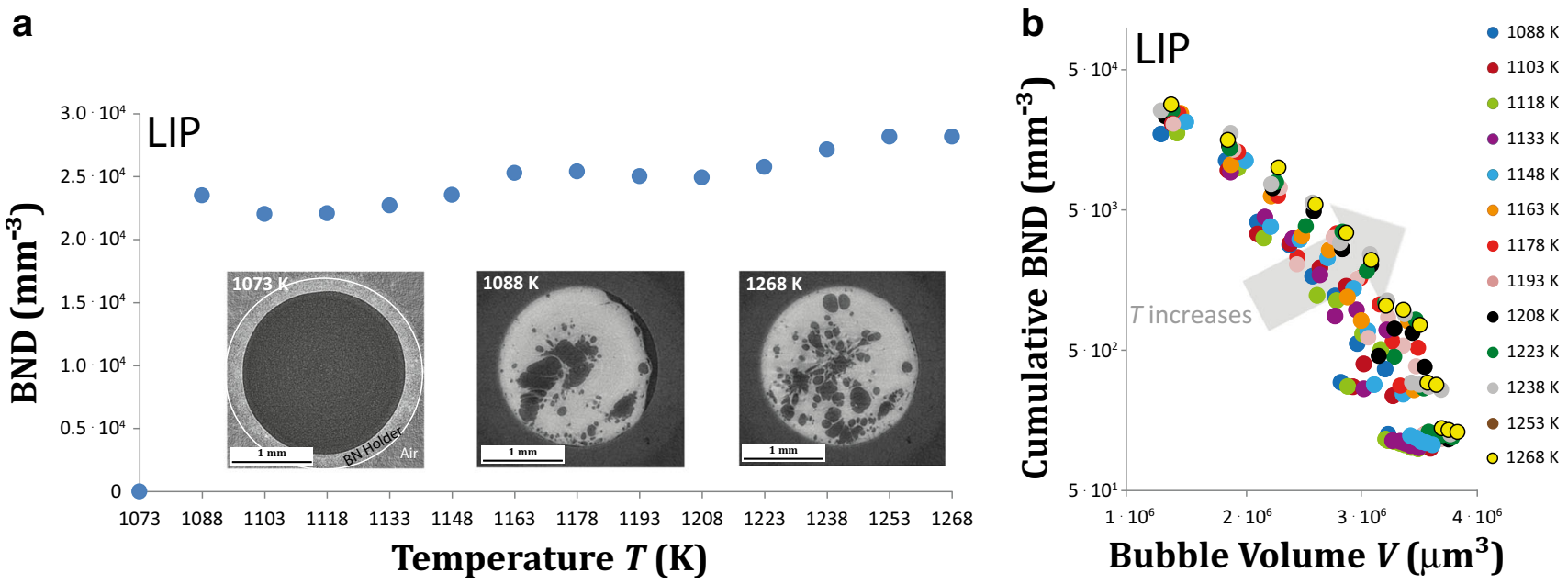

C

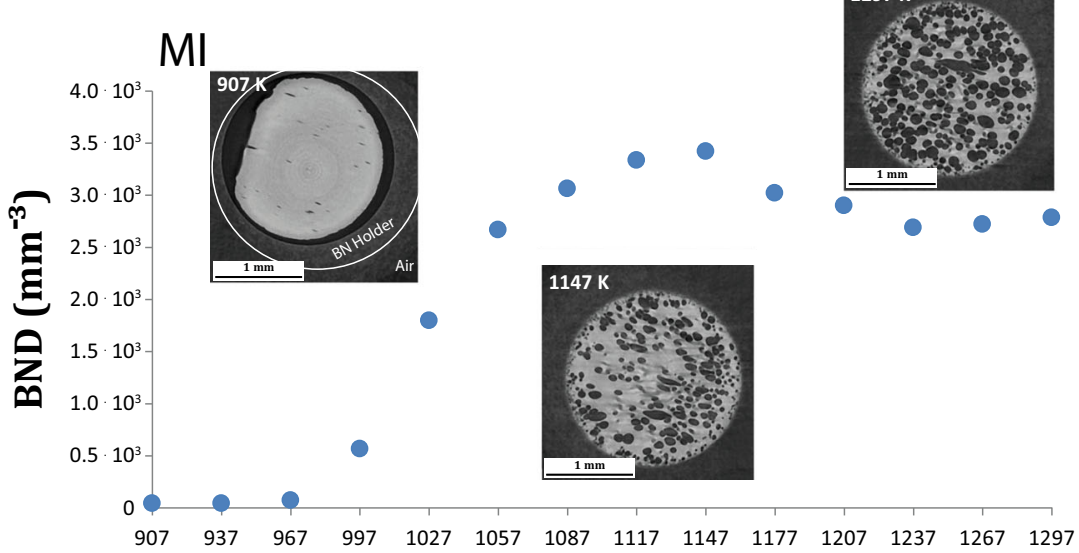

Temperature $T(\mathrm{~K})$

Fig. 7 Bubble number density (BND) as a function of temperature for: (a) LIP, and (c) MI samples. Representative 2D greyscale tomographic slices are included for each sample as a visual representation of the change in the microstructure during the respective dynamic sequences. Cumulative bubble size distributions (BND vs. bubble volume) during bubble growth in: (b) LIP and (d) MI samples at different temperatures. Both samples display a range of BNDs and bubble volumes at each

characteristic timescales for diffusion $\left(\tau_{d}\right)$ and viscous deformation/relaxation $\left(\tau_{v}\right)$ are:

$\tau_{d}=\frac{r^{2}}{D_{\mathrm{H}_{2} \mathrm{O}}}$

$\tau_{v}=\frac{\eta_{\text {melt }}}{\Delta P_{g}}$

where $D_{\mathrm{H}_{2} \mathrm{O}}$ is the $\mathrm{H}_{2} \mathrm{O}$ diffusion coefficient or diffusivity (Zhang et al. 2000). $\eta_{\text {melt }}$ is the melt viscosity, and $\Delta P_{g}$ is the gas overpressure. Here, we refer to the closed-system end-member case and calculate $\Delta P_{g}$ using the ideal gas law and the equation of state for $\mathrm{H}_{2} \mathrm{O}$ reported in Pitzer and Sterner (1994) (Table 1; see also Pistone 2012). $\mathrm{H}_{2} \mathrm{O}$ diffusion in highly viscous rhyolitic melts at low $\mathrm{H}_{2} \mathrm{O}$ contents $(<<1 \mathrm{wt} . \%)$, such as those explored in our study, is extremely temperature. In the BND analyses, all bubbles more than $0.9 \mathrm{~mm}$ from the centre of the sample cylinder are excluded because of boundary effects in the subsequent analysis (Mader et al. 2012). Likewise, bubble diameters smaller than $80 \mu \mathrm{m}$ were excluded from the analysis because their behaviour is more erratic and not indicative of the general trends of BNDs; in total $2 \%$ of the data volume was excluded from the analyses

slow $\left(D_{\mathrm{H}_{2} \mathrm{O}}=8.0 \cdot 10^{-13}\right.$ to $1.4 \cdot 10^{-11} \mathrm{~m}^{2} / \mathrm{s}$, in the temperature range $883-1253 \mathrm{~K}$; Jambon et al. 1992; below $883 \mathrm{~K}$, any determination of $D_{\mathrm{H}_{2} \mathrm{O}}$ is impossible due to the increase of the glass transition temperature of the experimental charges with $\mathrm{H}_{2} \mathrm{O}$ removal from the silicic melt during experiments).

In order to determine whether gas exsolution is dominantly controlled by $\mathrm{H}_{2} \mathrm{O}$ diffusion or gas expansion, the nondimensional Péclet number $(\mathrm{Pe})$, which is the ratio between the characteristic timescales for diffusion (Eq. 1) and viscous deformation/relaxation (Eq. 2), must be determined (Navon et al. 1998):

$\mathrm{Pe}=\frac{\tau_{d}}{\tau_{v}}=\frac{\Delta P_{g} r^{2}}{\eta_{\text {melt }} D_{\mathrm{H}_{2} \mathrm{O}}}$

In our experiments gas exsolution occurs under conditions of $\mathrm{Pe}>>1$, at temperatures higher than $967 \mathrm{~K}$ (Table 1), and in a 
Fig. 8 The evolution of bubble size distributions with temperature in the MI sample based on five different size classes: 70, 90, 110, 130, and $150 \mu \mathrm{m}$. Each class has a $20 \mu \mathrm{m}$ range, where, for example, the $70 \mu \mathrm{m}$ class represents bubbles that have a radius between 50 and $70 \mu \mathrm{m}$. Bubbles larger than the $150 \mu \mathrm{m}$ class are not found in the MI sample; bubbles smaller than a $40 \mu \mathrm{m}$ radius are excluded from the present analysis as outlined in the caption of Fig. 7

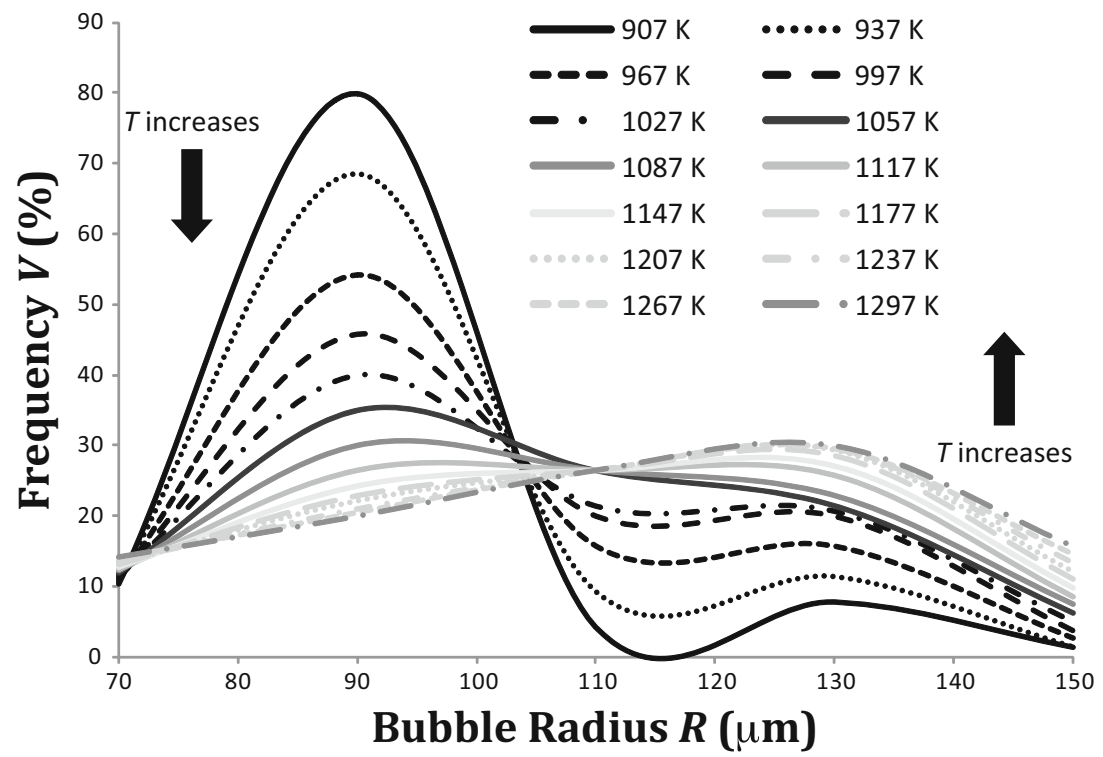

short time interval $(<15 \mathrm{~s})$, and, therefore, diffusive mass transfer can be considered unimportant relative to the rate of expansion.

To further examine $\mathrm{H}_{2} \mathrm{O}$ diffusion, laboratory time-dependent experiments from previous studies were performed with silicic melts at a specific temperature for different durations of time, ranging from hours to days. The bubble nucleation rate decayed with time because the volume available for progressive nucleation and the degree of $\mathrm{H}_{2} \mathrm{O}$ supersaturation at the specified temperature decreased with time (Bagdassarov et al. 1996). In the experiments of Bagdassarov et al. (1996). the time delay for bubble nucleation (also known as induction time or lag time) characterises the capacity of the system to reorganise itself until a steady-state flux of nuclei is generated (Toschev 1973). Conversely, in short duration $(<15 \mathrm{~s})$ experiments like those we conducted in this study, with temperatures increasing at a constant rate $(15$ to $30 \mathrm{~K} / \mathrm{s})$ and $\mathrm{Pe}>>1, \mathrm{H}_{2} \mathrm{O}$ diffusion does not keep up with the temperature increase (i.e. $\mathrm{H}_{2} \mathrm{O}$ diffusion is very slow at low $\mathrm{H}_{2} \mathrm{O}$ contents in silicic melts; Zhang et al. 1991). and thus, the degree of $\mathrm{H}_{2} \mathrm{O}$ supersaturation is expected to increase with time. This may explain the bubble growth "delay" observed in our experiments conducted with bubble-bearing systems (Fig. 6b). Such a bubble growth "delay" should favour $\mathrm{H}_{2} \mathrm{O}$ supersaturation of silicate melt, and the resulting $\eta_{\text {melt }}$ should be lower than that computed here (Fig. 4c), due to the presence of supersaturated $\mathrm{H}_{2} \mathrm{O}$. This implies that the degree of $\mathrm{H}_{2} \mathrm{O}$ supersaturation may control the kinetics of degassing and the rate of volume expansion of the gas-melt suspension (i.e. the rate of $\beta$ increase; Mangan and Sisson 2000).

\section{Degassing modalities in bubble-free and bubble-bearing systems}

During bubble growth, the $\beta$-temperature diagrams (Fig. 6) show different modalities of degassing between samples initially containing bubbles (MI) and initially bubble-free glasses (LIP). The LIP sample shows two principal segments: (a) initial rapid increase of bubble volume, and (b) gas exsolution at constant $\beta$ (Fig. 6a). The MI sample displays three main segments: (i) time delay for bubble nucleation accompanied by $\mathrm{H}_{2} \mathrm{O}$ flux into the pre-existing gas bubbles; (ii) a vesiculation or $\beta$-increase regime; and (iii) a "quasi-steady-state" characterised by constant $\beta$ (Fig. 6b) due to $\mathrm{H}_{2} \mathrm{O}$ exhaustion in the melt $(\leq 0.1$ wt.\%; Fig. 4). In the MI sample, $\beta$ follows a sigmoidal trend, as predicted by the Avrami equation (Avrami 1939; 1940). but the final true steady-state regime is never achieved (Fig. 6b). Conversely, the LIP sample is characterised by a large release of gas induced by bubble coalescence after the initial rapid increase of $\beta$ (Fig. 4a). The subsequent "quasi-steady-state" regime, accompanied by only a slight increase of $\beta(\Delta \beta<0.2$; Fig. 6a), together with a strong increase of bubble anisotropy at the temperature where the bubble volume increases suddenly (1088 K), confirms the release of gas through gas channels (Fig. 6a). The LGM sample does not display significant vesiculation $(\beta<0.04$; Fig. 6a); this might suggest that the combination of short experimental duration $\left(<14\right.$ seconds), low- $\mathrm{H}_{2} \mathrm{O}$ content in the initial glass ( $\leq 0.1 \mathrm{wt} . \%$ ), and initial high glass transition temperature (975 K, which then increases during gas exsolution) hampered any considerable vesiculation (Fig. 4a), even in presence of oxides that could have acted as preferential nucleation sites (e.g. Hurwitz and Navon 1994). The CAN sample shows hybrid behaviour between the LIP and MI samples. Indeed, the CAN sample displays an initial sharp increase in $\beta$ up to 0.6 (Fig. 6b), followed by a slow increase up to $0.74\left(=\beta_{\max }\right)$ in a "quasi-steady-state" manner, with no evident bubble coalescence, which is also confirmed by the lack of $\mathrm{H}_{2} \mathrm{O}$ released during KFT analyses (Fig. 4b). Overall, the behaviour of the CAN sample is similar to that of the MI sample, except for the initial onset of vesiculation, which is similar to the LIP sample. 
Table 1 Summary of the textural and physical parameters of the MI and LIP samples (see experiments "mi3_Dynamic" and "lip4_Dynamic", respectively; Table 1B in Appendix), selected as a representation for bubble growth in highly viscous bubble-bearing magmas in this contribution

\begin{tabular}{|c|c|c|c|c|c|c|c|c|c|c|c|}
\hline \multicolumn{12}{|c|}{ LIP sample } \\
\hline$T(\mathrm{~K})$ & $\beta$ & Apparent $\mathrm{H}_{2} \mathrm{O}$ (wt.\%) & \multicolumn{9}{|l|}{$\log \eta_{\text {melt }}(\mathrm{Pa} \cdot \mathrm{s})$} \\
\hline 1073 & 0.00 & 0.00 & \multicolumn{9}{|l|}{8.45} \\
\hline 1088 & 0.35 & 0.35 & \multicolumn{9}{|l|}{9.18} \\
\hline 1103 & 0.34 & 0.35 & \multicolumn{9}{|l|}{8.94} \\
\hline 1118 & 0.33 & 0.36 & \multicolumn{9}{|l|}{8.74} \\
\hline 1133 & 0.34 & 0.36 & \multicolumn{9}{|l|}{8.52} \\
\hline 1148 & 0.37 & 0.37 & \multicolumn{9}{|l|}{8.33} \\
\hline 1163 & 0.41 & 0.38 & \multicolumn{9}{|l|}{8.15} \\
\hline 1178 & 0.41 & 0.39 & \multicolumn{9}{|l|}{7.98} \\
\hline 1193 & 0.40 & 0.40 & \multicolumn{9}{|l|}{7.81} \\
\hline 1208 & 0.41 & 0.41 & \multicolumn{9}{|l|}{7.64} \\
\hline 1223 & 0.43 & 0.42 & \multicolumn{9}{|l|}{7.49} \\
\hline 1238 & 0.45 & 0.43 & \multicolumn{9}{|l|}{7.33} \\
\hline 1253 & 0.48 & 0.44 & \multicolumn{9}{|l|}{7.18} \\
\hline 1268 & 0.48 & 0.45 & \multicolumn{9}{|l|}{7.04} \\
\hline \multicolumn{12}{|c|}{ MI sample } \\
\hline$T(\mathrm{~K})$ & $\beta$ & Apparent $\mathrm{H}_{2} \mathrm{O}$ (wt.\%) & $\log \eta_{\text {melt }}(\mathrm{Pa} \cdot \mathrm{s})$ & $r(\mu \mathrm{m})$ & $r^{\prime}(\mu \mathrm{m} / \mathrm{s})$ & $\Delta \mathrm{P}_{\mathrm{g}}(\mathrm{MPa})$ & $\mathrm{D}\left(\mathrm{H}_{2} \mathrm{O}\right)\left(\mu \mathrm{m}^{2} / \mathrm{s}\right)$ & $1_{c}(\mu \mathrm{m})$ & $\tau_{\mathrm{d}}(\mathrm{s})$ & $\tau_{\mathrm{v}}(\mathrm{s})$ & $\mathrm{Pe}$ \\
\hline 907 & 0.02 & 0.10 & 11.49 & 93 & 2 & 1.11 & 0.11 & 0.33 & $8 \mathrm{E}+04$ & $3 \mathrm{E}+05$ & 0 \\
\hline 937 & 0.02 & 0.10 & 10.80 & 95 & 4 & 1.24 & 0.16 & 0.40 & $6 \mathrm{E}+04$ & $5 \mathrm{E}+04$ & 1 \\
\hline 967 & 0.02 & 0.11 & 10.22 & 99 & 3 & 0.83 & 0.24 & 0.49 & $4 \mathrm{E}+04$ & $2 \mathrm{E}+04$ & 2 \\
\hline 997 & 0.05 & 0.12 & 9.68 & 102 & 1 & 0.67 & 0.35 & 0.59 & $3 \mathrm{E}+04$ & $7 \mathrm{E}+03$ & 4 \\
\hline 1027 & 0.10 & 0.12 & 9.14 & 103 & 2 & 0.69 & 0.51 & 0.71 & $2 \mathrm{E}+04$ & $2 \mathrm{E}+03$ & 10 \\
\hline 1057 & 0.20 & 0.14 & 8.72 & 105 & 2 & 0.91 & 0.73 & 0.86 & $2 \mathrm{E}+04$ & $6 \mathrm{E}+02$ & 26 \\
\hline 1087 & 0.33 & 0.14 & 8.25 & 107 & 1 & 1.04 & 0.99 & 1.00 & $1 \mathrm{E}+04$ & $2 \mathrm{E}+02$ & 68 \\
\hline 1117 & 0.48 & 0.15 & 7.84 & 108 & 1 & 1.04 & 1.38 & 1.17 & $8 \mathrm{E}+03$ & $7 \mathrm{E}+01$ & 125 \\
\hline 1147 & 0.62 & 0.15 & 7.43 & 109 & 1 & 1.10 & 1.79 & 1.34 & $7 \mathrm{E}+03$ & $2 \mathrm{E}+01$ & 271 \\
\hline 1177 & 0.67 & 0.16 & 7.08 & 110 & 1 & 1.04 & 2.32 & 1.52 & $5 \mathrm{E}+03$ & $1 \mathrm{E}+01$ & 453 \\
\hline 1207 & 0.77 & 0.16 & 6.71 & 111 & 0 & 1.04 & 2.95 & 1.72 & $4 \mathrm{E}+03$ & $5 \mathrm{E}+00$ & 841 \\
\hline 1237 & 0.84 & 0.17 & 6.40 & 111 & 1 & 1.13 & 3.72 & 1.93 & $3 \mathrm{E}+03$ & $2 \mathrm{E}+00$ & 1494 \\
\hline 1267 & 0.85 & 0.17 & 6.08 & 112 & 1 & 1.13 & 4.72 & 2.17 & $3 \mathrm{E}+03$ & $1 \mathrm{E}+00$ & 2526 \\
\hline 1297 & 0.87 & 0.18 & 5.80 & 113 & 1 & $/(*)$ & $/(*)$ & $/(*)$ & $/(*)$ & $/(*)$ & $/(*)$ \\
\hline
\end{tabular}

Parameters $\Delta P_{g}, D, l_{c}, \tau_{d}$, and $\tau_{v}$ are calculated only in the MI sample where gas permeability is absent

$T$ temperature, $\beta$ bubble volume fraction, $V_{\beta}$ total bubble volume, Apparent $\mathrm{H}_{2} \mathrm{O}$ cumulative extracted $\mathrm{H}_{2} \mathrm{O}$ from the cylindrical LIP and MI samples, measured by KFT technique, $\log \eta_{\text {melt }}$ logarithm of melt viscosity calculated with the model of Giordano et al. (2008). $r$ weighted average bubble radius; $r^{\prime}$ bubble radius growth rate, $\Delta P_{g}$ gas overpressure, $D_{\mathrm{H}_{2} \mathrm{O}}$ diffusion coefficient or diffusivity of $\mathrm{H}_{2} \mathrm{O}$ (Zhang et al. 2000). $l_{c}$ diffusion characteristic length, $\tau_{d}$ diffusion timescale, $\tau_{v}$ viscous timescale, $P e$ Péclet number.

$(*)=$ no available data for $\mathrm{H}_{2} \mathrm{O}$ from the work of Pitzer and Sterner (1994).

The initial bubble bursting could be related to an initial lower $\eta_{\text {melt }}$ of the phonolitic CAN sample than those of the other rhyolitic samples investigated here (Figs. 1 and 4c; Table 1A in the Appendix).

\section{Gas connectivity in bubble-free and bubble-bearing systems: the importance of the initial presence of gas bubbles in magmas}

It is known that gas connectivity occurs when a critical $\beta$ is achieved (Sahimi 1994). According to the standard percolation theory, bubbles form an interconnected network when a threshold value of $\beta_{c}$ is reached and, beyond that, gas permeability $(k)$ increases with increasing $\beta$, following a power-law relationship (Rust and Cashman 2011):

$\mathrm{k} \propto\left(\beta-\beta_{c}\right)^{b}$

where $b$ depends on pore geometry $(b=2$ as derived from Poiseuille flow and Darcy's law equations; Wright et al. 2009, and references therein). In the standard percolation theory, if uniform spheres are placed randomly in a much larger sample volume and the spheres are allowed to overlap/ 
connect, a cluster of touching and overlapping spheres will span the sample volume until the critical $\beta_{c}=0.29$ is obtained (Sahimi 1994). Following this theory, some studies (e.g. Polacci et al. 2008) assumed that magma becomes permeable when $\beta_{c}=0.30$. However, in numerical simulations (e.g. Garboczi et al. 1995) as well as in experimental studies where shear deformation induced bubble coalescence (Okumura et al. 2006, 2008, 2009, 2013). the percolation threshold was reduced by bubble deformation, where oblate objects increased the likelihood of bubble connectivity and outgassing from the magmatic system (Caricchi et al. 2011; Pistone et al. 2012; Shields et al. 2014). Gas exsolution in the LIP sample is consistent with the standard percolation theory, since bubble connectivity is initiated at $\beta=0.35\left(>\beta_{c}=0.30\right)$ after the initial vesiculation burst at $1088 \mathrm{~K}$ (Fig. 6a). In contrast, the percolation threshold is never achieved in systems initially containing bubbles (MI and CAN), where the final bubble content reaches values close to or above the value of maximum packing fraction $\left(\beta_{\max }=0.74\right.$; Fig. $\left.6 \mathrm{~b}\right)$. There are numerous studies testifying that bubble-bearing suspensions can reach $\beta>>$ 0.30 without becoming permeable (e.g. Blower 2001). this suggests that parameters other than the percolation threshold might be important in determining permeability in bubble-rich systems (Okumura et al. 2009).

The striking difference in vesiculation dynamics between the MI (gas expansion) and LIP (gas connectivity) samples demonstrates that Eq. 4 suffers from the limitations of the percolation theory, which does not take into account either the bulk volume increase during vesiculation or the time required to thin the films that separate individual bubbles (Rust and Cashman 2011, and references therein). Therefore, the value of $\beta_{c}=0.30$ obtained from standard percolation theory provides only the minimum porosity at which connected bubbles may form a permeable network during vesiculation. In contrast to the case of the LIP sample, the MI sample does not achieve gas permeability and outgassing because of the initial presence of gas bubbles prior to heating. In our experiments, the influence of the heating rate is probably not a significant factor determining the conditions of gas permeability versus gas expansion. In fact, $\mathrm{MI}$ and $\mathrm{CAN}$ samples were heated at different rates $(30 \mathrm{~K} / \mathrm{s}$ in $\mathrm{MI}$ and $15 \mathrm{~K} / \mathrm{s}$ in CAN), but both systems did not experience gas permeability and outgassing (Fig. 6b). The results of this study indicate that the presence or absence of initial gas bubbles in the system is an important factor in determining the occurrence of gas connectivity in magmas. In the absence of gas bubbles and other initial heterogeneities (e.g. crystals and/or large chemical heterogeneities in the melt), nucleation of bubbles can theoretically occur everywhere in the melt domain. This would increase the probability of connectivity between neighbour bubbles nucleating and growing over a short distance $(<3 \mu \mathrm{m})$. Conversely, the initial presence of gas bubbles, combined with the initial spatial distribution of bubbles (i.e. distance between bubbles is
$>10 \mu \mathrm{m}$ in $\mathrm{MI}$ and CAN samples), drives gas exsolution to pre-existing sites that will unlikely connect. Therefore, we can say that: (i) in bubble-free magmas, bubble connectivity may follow the general principles of the percolation theory; and (ii) conversely, in bubble-bearing systems, bubble connectivity could be hampered and magmas can expand well beyond the percolation threshold without becoming permeable.

It is also known that bubble connectivity is a function of the surface tension between gas and surrounding melt, which, in turn, depends on temperature, pressure, $\mathrm{H}_{2} \mathrm{O}$ content of the melt phase, and $\eta_{\text {melt }}$ (Bagdassarov et al. 2000; Mangan and Sisson 2000; Gardner and Ketcham 2011). However, the data acquired in this study do not allow for estimations of surface tension nor its potential correlation with the vesiculation process observed in $\mathrm{H}_{2} \mathrm{O}$-poor $(<<1$ wt.\%) silicic melts during the $\mathrm{X}$-ray tomographic microscopy experiments.

\section{Conclusions}

Our results highlight how pre-existing gas bubbles may strongly affect the dynamics of vesiculation (bubble nucleation, growth, coalescence and outgassing) in a silicic magmatic system. Crystal-free, volatile-undersaturated magmas (i.e. no initial gas bubbles) show localised nucleation and growth of bubbles (heterogeneous vesiculation driven by the chemical heterogeneities in the initial glass? homogeneous bubble nucleation, growth, and coalescence occurring almost simultaneously?), which tend to coalesce and generate permeable pathways for gas escape at $>30$ vol. $\%$ gas content, following the predictions of the standard percolation theory. Conversely, when a crystal-free magma is volatile-saturated (i.e. presence of initial gas bubbles), gas exsolution is controlled by the existence of bubbles in the magmatic system prior to heating, and magmas can extensively expand without the development of bubble connectivity and outgassing. It is important to bear in mind that samples used in this study are initially $\mathrm{H}_{2} \mathrm{O}$-poor ( $<<1$ wt. \%) due to the imposed experimental conditions (high-temperature experiments conducted at room pressure). Moreover, our experiments were conducted with heating, thereby melt viscosity decreases with time.

In a natural scenario, magma residing in a shallow reservoir $(\leq 6 \mathrm{~km})$ is expected to be richer in $\mathrm{H}_{2} \mathrm{O}$ dissolved in the melt ( $\leq 4$ wt. $\%$ ), and, during its ascent, that magma should experience decompression and relative cooling. The vesicularities obtained in our experiments match those found in natural samples. However, the bubble number densities presented are much lower than those observed in natural volcanic vesicular samples. Therefore, at the present stage, our experimental results provide qualitative insights into the processes of bubble nucleation and growth occurring in resident and ascending magmas. But our results also underline the importance of the initial presence or absence of gas bubbles, which appears to 
have a significant impact on the modality of degassing in a magma stored in a reservoir or ascending in a volcanic conduit. The principal difference in degassing behaviour observed in this study could imply that eruptions fed by magmas that are volatile-saturated already in the magma chamber have a higher probability of being explosive than eruptions associated with resident volatile-undersaturated magmas.

Acknowledgments Swiss National Science Foundation (grant 200020-120221) supported the present research. We wish to thank: G. Mikuljan, U. Graber and B. Buse for the technical support at the TOMCAT beamline, ETH-Zurich, and University of Bristol respectively; P. Benson, B.S.G. Almqvist, and C. Madonna for assisting at the TOMCAT beamline; A. Rust and B. Andrews for fruitful discussions; two anonymous reviewers for helpful comments on the earlier version of the manuscript; the Associate Editor J. Taddeucci for editorial handling. J.L. Fife also acknowledges the CCMX and PSI for funding the development of the laser-based heating system. This work is dedicated to Luigi Burlini.

\section{References}

Avrami M (1939) Kinetics of phase change. I. General theory. J Chem Phys 7:1103-1112

Avrami M (1940) Kinetics of phase transition. II. Transformation time relations. J Chem Phys 8:212-224

Bagdassarov NS, Dingwell DB, Wilding MC (1996) Rhyolite magma degassing: an experimental study of melt vesiculation. Bull Volcanol 57:587-601

Bagdassarov NS, Dorfman A, Dingwell DB (2000) Effect of alkalis, phosphorus, and water on the surface tension of haplogranite melt. Am Mineral 85:33-40

Bai L, Baker DR, Rivers M (2008) Experimental study of bubble growth in Stromboli basalt melts at $1 \mathrm{~atm}$. Earth Planet Sci Lett 267:533547

Baker DR, Brun F, O'Shaugnnessy C, Mancini L, Fife JL, Rivers M (2012) A four-dimensional X-ray tomographic microscopy study of bubble growth in basaltic foam. Nat Commun 3:1135. doi:10. 1038 /ncomms 2134

Behrens H, Romano C, Nowak M, Holtz F, Dingwell DB (1996) Nearinfrared spectroscopic determination of water species in glasses of system $\mathrm{MAlSi}_{3} \mathrm{O}_{8}(\mathrm{M}=\mathrm{Li}, \mathrm{Na}, \mathrm{K})$ : an interlaboratory study. Chem Geol 128:41-63

Bikerman JJ (1973) Foams. Springer, Berlin Heidelberg New York

Blower JD (2001) Factors controlling permeability-porosity relationships in magma. Bull Volcanol 63:497-504

Burgisser A, Gardner JE (2005) Experimental constraints on degassing and permeability in volcanic conduit flow. Bull Volcanol 67:42-56

Caricchi L, Pommier A, Pistone M, Castro J, Burgisser A, Perugini D (2011) Strain-induced magma degassing: insights from simple-shear experiments on bubble bearing melts. Bull Volcanol 73:1245-1257

Castro JM, Burgisser A, Schipper CI, Mancini S (2012) Mechanisms of bubble coalescence in silicic magmas. Bull Volcanol 74:2339-2352

Fife JL, Rappaz M, Pistone M, Celcer T, Mikuljan G, Stampanoni M (2012) Development of a laser-based heating system for in-situ synchrotron-based X-ray tomographic microscopy. J Synchrotron Radiat 19:352-358

Fink JH (1983) Structure and emplacement of a rhyolitic obsidian flow. Geol Soc Am Bull 94:362-380

Fischer K (1935) New method for the quantum analytical instruction of the water proofing from liquids and solid bodies. Angew Chem 48: 0394-0396
Fisher RV, Schmincke H-U (1984) Pyroclastic rocks. Springer, Berlin Heidelberg New York

Gaonac'h H, Lovejoy S, Schertzer D (2005) Scaling vesicle distributions and volcanic eruptions. Bull Volcanol 67:350-357

Garboczi EJ, Snyder KA, Douglas JF, Thorpe MF (1995) Geometrical percolation threshold of overlapping ellipsoids. Phys Rev E 52:819 828

Gardner JE, Ketcham RA (2011) Bubble nucleation in rhyolite and dacite melts: temperature dependence of surface tension. Contrib Mineral Petrol 162:929-943

Gardner JE, Hilton M, Carroll MR (1999) Experimental constraints on degassing of magma: isothermal bubble growth during continuous decompression from high pressure. Earth Planet Sci Lett 168:201218

Giordano D, Russell JK, Dingwell DB (2008) Viscosity of magmatic liquids: a model. Earth Planet Sci Lett 271:123-134

Gondé C, Martel C, Pichavant M, Bureau H (2011) In situ bubble vesiculation in silicic magmas. Am Mineral 96:111-124

Gonnermann HM, Manga M (2007) The fluid mechanics inside a volcano. Annu Rev Fluid Mech 39:321-56

Gottsmann J, Dingwell DB (2001) The cooling of frontal flow ramps: a calorimetric study on the Rocche Rosse rhyolite flow, Lipari, Aeolian Islands, Italy. Terra Nov. 13:157-164

Hurwitz S, Navon O (1994) Bubble nucleation in rhyolitic melts: experiments at high pressure, temperature, and water content. Earth Planet Sci Lett 122:267-280

Jambon A, Zhang Y, Stolper EM (1992) Experimental dehydration of natural obsidian and estimation of $\mathrm{D}_{\mathrm{H}_{2} \mathrm{O}}$ at low water contents. Geochim Cosmochim Acta 56:2931-2935

Klug C, Cashman KV, Bacon CR (2002) Structure and physical characteristics of pumice from the climactic eruption of Mount Mazama (Crater Lake), Oregon. Bull Volcanol 64:486-501

Kraynik AM (1988) Foam flows. Annu Rev Fluid Mech 20:325-357

Larsen JF, Denis MH, Gardner JE (2004) Experimental study of bubble coalescence in rhyolitic and phonolitic melts. Geochim Cosmochim Acta 68:333-344

Le Maitre RW, Streckeisen A, Zanettin B, Le Bas MJ, Bonin B, Bateman, P, Bellieni, Dudek A, Efremova S, Keller, J, Lameyre J, Sabine PA, Schmid, R, Sørensen H, Woolley AR (2002) Igneous rocks: a classification and glossary of terms, recommendations of the International Union of Geological Sciences, Subcommission of the Systematics of Igneous Rocks. Cambridge University Press, ISBN 0-521-66215-X

Mader K, Mokso R, Raufaste C, Dollet B, Santucci S, Lambert J, Stampanoni M (2012) Quantitative 3D characterization of cellular materials: segmentation and morphology of foam. Coll Surf A Physicochem Eng Aspects ISSN 0927-7757, 10.1016/j.colsurfa. 2012.09.007

Madonna C, Quintal B, Frehner M, Almqvist BSG, Tisato N, Pistone M, Marone F, Saenger EH (2013) Synchrotron-based X-ray tomographic microscopy for rock physics investigations. Geophysics 78:D53D64

Mangan MT, Sisson TW (2000) Delayed, disequilibrium degassing in rhyolite magma: decompression experiments and implications for explosive volcanism. Earth Planet Sci Lett 183:441-455

Melnik O, Barmin AA, Sparks RSJ (2005) Dynamics of magma flow inside volcanic conduits with bubble overpressure buildup and gas loss through permeable magma. J Volcanol Geotherm Res 143:53-68

Mokso R, Marone F, Stampanoni M (2010) Real time tomography at Swiss Light Source AIP. Conf Proc 1234:87-90

Mortazavi B, Pereira LFC, Jiang J-W, Rabczuk T (2015) Modeling heat conduction in polycrystalline hexagonal boron-nitride films. Nature Scientific Reports 5, doi:10.1038/srep13228 
Murase T, McBirney A (1973) Properties of some common igneous rocks and their melts at high temperatures. Geol Soc Am Bull 84:35363592

Namiki A, Manga M (2005) Response of a bubble bearing viscoelastic fluid to rapid decompression: implications for explosive volcanic eruptions. Earth Planet Sci Lett 236:269-284

Navon O, Chekhmir A, Lyakhovsky V (1998) Bubble growth in highly viscous melts: theory, experiments, and autoexplosivity of dome lavas. Earth Planet Sci Lett 160:763-776

Okumura S, Nakamura M, Tsuchiyama A (2006) Shear-induced bubble coalescence in rhyolitic melts with low vesicularity. Geophys Res Lett 33, L20316

Okumura S, Nakamura M, Tsuchiyama A, Nakano T, Uesugi K (2008) Evolution of bubble microstructure in sheared rhyolite: formation of a channel-like bubble network. J Geophys Res 113, B07208. doi:10. 1029/2007JB005362

Okumura S, Nakamura M, Takeuchi S, Tsuchiyama A, Nakano T, Uesugi $\mathrm{K}$ (2009) Magma deformation may induce non-explosive volcanism via degassing through bubble networks. Earth Planet Sci Lett 281: 267-274

Okumura S, Nakamura M, Uesugi K, Tsuchiyama A, Nakano T, Fujioka $\mathrm{T}$ (2013) Coupled effect of magma degassing and rheology on silicic volcanism. Earth Planet Sci Lett 362:163-170

Pistone, M. (2012) Physical properties of crystal- and bubble-bearing magmas. Dissertation N ${ }^{\circ}$ 20698, ETH-Zurich, Switzerland

Pistone M, Caricchi L, Ulmer P, Burlini L, Ardia P, Reusser E, Marone F, Arbaret L (2012) Deformation experiments of bubble- and crystalbearing magmas: rheological and microstructural analysis. J Geophys Res 117, doi:10.1029/2011JB008986

Pistone M, Caricchi L, Ulmer P, Reusser E, Ardia P (2013) Rheology of volatile-bearing crystal mushes: mobilization vs. viscous death. Chem Geol 345:16-39

Pistone M, Arzilli F, Dobson KJ, Cordonnier B, Reusser E, Ulmer P, Marone F, Whittington AG, Mancini L, Fife JL, Blundy JD (2015) Gas-driven filter pressing in magmas: insights into in-situ melt segregation from crystal mushes. Geology. doi:10.1130/G36766.1

Pitzer KS, Sterner SM (1994) Equations of state valid continuously from zero to extreme pressures for $\mathrm{H}_{2} \mathrm{O}$ and $\mathrm{CO}_{2}$. J Chem Phys 101: 3111-3116

Polacci M, Baker DR, Bai LP, Mancini L (2008) Large vesicles record pathways of degassing at basaltic volcanoes. Bull Volcanol 70: $1023-1029$
Rust AC, Cashman KV (2011) Permeability controls on expansion and size distributions of pyroclasts. J Geophys Res 116, B11202. doi:10. 1029/2011JB008494

Rust AC, Manga M, Cashman KV (2003) Determining flow type, shear rate and shear stress in magmas from bubble shapes and orientations. J Volcanol Geotherm Res 122:11-132

Sahimi M (1994) Applications of percolation theory. Taylor and Francis, London

Shields J, Mader HM, Pistone M, Caricchi L, Floess D, Putlitz B (2014) Strain-induced outgassing of three-phase magmas during simple shear, J. Geophys. Res. 119, doi:10.1002/2014JB011111

Sparks RSJ (2003) Dynamics of magma degassing. In Oppenheimer C, Pyle DM, Barclay J (eds). Volcanic Degassing. Geol Soc Lond Spec Pub 213:5-22

Sparks RSJ, Barclay J, Jaupart C, Mader HM, Phillips JC (1994) Physical aspects of magma degassing I. Experimental and theoretical constraints on vesiculation. In Carroll MR, Holloway JR (eds). Volatiles in Magmas, Rev Mineral 30:413-445

Stampanoni M, Groso A, Isenegger A, Mikuljan G, Chen Q, Bertrand A, Henein S, Betemps R, Frommherz U, Böhler P, Meister D, Lange M, Abela R (2006) Trends in synchrotron-based tomographic imaging: the SLS experience. Dev X-ray Tom V - Proc SPIE 6318, doi: $10.1117 / 12.679497$

Stevenson RJ, Briggs RM, Hodder PW (1993) Emplacement history of a low-viscosity, fountain-fed pantelleritic lava flow. J Volcanol Geotherm Res 57:39-56

Takeuchi S, Nakashima S, Tomiya A, Shinohara H. (2005) Experimental constraints on the low gas permeability of vesicular magma during decompression. Geophys Res Lett 32, doi:10.1029/2005GL022491

Toschev S (1973) Homogeneous nucleation. In: Hartman P (ed) Crystal growth: an introduction. Elsevier, New York

Wiley-VCH (1999) Ullmann's Encyclopedia of Industrial Chemistry. Sixth Edition, doi: 10.1002/14356007

Wright HMN, Weinberg RF (2009) Strain localization in vesicular magma: implications for rheology and fragmentation. Geology 37:1023-1026

Wright HMN, Cashman KV, Gottesfeld EH, Roberts JJ (2009) Pore structure of volcanic clasts: measurements of permeability and electrical conductivity. Earth Planet Sci Lett 280:93-104

Zhang Y, Stolper EM, Wasserburg GJ (1991) Diffusion of water in rhyolitic glasses. Geochim Cosmochim Acta 55:441-456

Zhang Y, Xu Z, Behrens H (2000) Hydrous species geospeedometer in rhyolite: improved calibration and application. Geochim Cosmochim Acta 64:3347-3355 